Disponível em:

http://editora.unoesc.edu.br/index.php/race

RACE, Joaçaba, v. 16, n. 3, p. 983-1008, set./dez. 2017

\title{
EFICIÊNCIA DE PREVISIBILIDADE ORÇAMENTÁRIA DA RECEITA PÚBLICA: UM ESTUDO EM MUNICÍPIOS DO ESTADO DO PARANÁ ENTRE OS EXERCÍCIOS 2002 E 2013
}

Efficiency of budget predictability of the public revenue: a study in municipalities of Paraná State between the financial years 2002 to 2013

Clóvis Fiirst

E-mail: cfiirst@gmail.com

Mestre em Ciências Contábeis pela Fundação Universidade Regional de Blumenau; Graduado em Ciências Contábeis pela Universidade Estadual do Oeste do Paraná; Professor na Universidade Estadual do Oeste do Paraná.

Edgar Pamplona

E-mail: edgarpamplona@hotmail.com Mestre e Graduado em Ciências Contábeis pela Fundação Universidade Regional de Blumenau; Professor na Fundação Universidade Regional de Blumenau.

Nelson Hein

E-mail: hein@furb.br

Pós-doutor na Área das Ciências Sociais Aplicadas pela The University of New México, Estados Unidos; Pós-doutor na Área das Ciências Exatas e da Terra pelo Instituto Nacional de Matemática Pura e Aplicada, Brasil; Professor no Programa de Pós-graduação em Ciências Contábeis da Fundação Universidade Regional de Blumenau.

Vinicius Costa da Silva Zonatto

E-mail: viniciuszonatto@gmail.com Doutor em Ciências Contábeis e Administração Fundação Universidade Regional de Blumenau; Mestre em Ciências Contábeis pela Fundação Universidade Regional de Blumenau; Professor no Programa de Pós-graduação em Ciências Contábeis da Fundação Universidade Regional de Blumenau. Endereço para contato: Rua Antônio da Veiga, 140, Sala D 202, Caixa postal 1507, Victor Konder, 89012-900, Blumenau, Santa Catarina, Brasil.

Artigo recebido em 06 de outubro de 2016. Aceito em 28 de junho de 2017. 
Resumo

Neste estudo objetivou-se verificar o nível de eficiência e elaborar um ranking da previsibilidade da receita orçamentária dos municípios do Estado do Paraná. Para tanto, realizou-se uma pesquisa descritiva, mediante análise documental, com abordagem quantitativa dos dados. Foram analisadas a receita prevista e arrecadada de 383 municípios paranaenses no período de 2002 a 2013, com uso de técnicas estatísticas de análise de clusters e TOPSIS. Os achados demonstraram que no período analisado a maioria dos munícipios do Estado do Paraná apresentou eficiência na previsibilidade de receitas orçamentárias. Constatou-se que o tamanho dos municípios, avaliado pelo número de habitantes, não influenciou a qualidade da eficiência da previsão da receita pública. Esses resultados revelam a necessidade de melhoria na elaboração da previsão orçamentária por parte dos municípios pesquisados, uma vez que uma previsão de receitas ineficaz pode comprometer as atividades de planejamento, avaliação, controle e accountability no que se refere à arrecadação e aplicação dos recursos públicos.

Palavras-chave: Eficiência da previsão da receita pública. Municípios do Estado do Paraná. Análise de cluster e TOPSIS.

Abstract

This study aimed to verify the level of efficiency and draw up a ranking of the predictability of budget revenues of the municipalities of Paraná State. Therefore, we conducted a descriptive research by documental analysis with quantitative data approach. We analyzed the expected and collected revenue of 383 municipalities of Paraná from 2002 to 2013, using statistical technique of clusters analysis and TOPSIS. The findings showed that in the period analyzed most of the municipalities of Paraná State showed efficiency in the predictability of budget revenues. It was found that the size of the municipalities, measured by the number of inhabitants, did not influence the quality of the efficiency of the predictability of the public revenue. These results reveal the need for improvement in the elaboration of the budget predictability by the cities surveyed, since an ineffective revenue predictability may undermine the planning, evaluation, control and accountability activity, in relation to the collection and use of public resources.

Keywords: Efficiency of predictability of the public revenue. Municipalities of Paraná State. Cluster analysis and TOPSIS.

\section{INTRODUÇÃO}

O orçamento é um importante instrumento de gestão utilizado no setor público (LEE; JOHNSON, 1977), sendo componente do sistema de controle gerencial nessas entidades (MWITA, 2000). Sua utilização auxilia os gestores na fixação dos 
planos e metas, bem como na identificação das necessidades de recursos para a manutenção dos serviços e a realização de obras e investimentos. Constitui-se, também, um instrumento de comunicação do ente público com a sociedade, contribuindo para a qualificação dos seus processos de accountability (SACRAMENTO, 2005).

A Secretaria de Orçamento Federal (SOF) define a receita pública como os recursos financeiros disponíveis, que ingressam no patrimônio público para atender às demandas da sociedade, as quais são transformadas em programas de governo (MINISTÉRIO DO PLANEJAMENTO, ORÇAMENTO E FESTÃO; SECRETARIA DE ORÇAMENTO FEDERAL, 2015). Não obstante as demais regras jurídicas, a receita pública integra as seguintes leis orçamentárias: Plano Plurianual (PPA), Lei de Diretrizes Orçamentárias (LDO) e Lei Orçamentária Anual (LOA), cuja previsão possui fulcro nos dispositivos da Lei de Finanças Públicas n. 4.320, de 1964, que explicita que os orçamentos compreenderão todas as receitas, inclusive as de operações de crédito. A Lei Complementar n. 101, de 2000 (Lei de Responsabilidade Fiscal (LRF)), também dispõe em seu artigo. 12 de mecanismo para a previsibilidade da receita orçamentária.

Scarpin e Slomski (2005, p. 2) explicam que com o advento da publicação da LRF “os procedimentos de natureza orçamentária passaram a ser influenciados significativamente mediante o fortalecimento de quatro dimensões: planejamento, controle, transparência e responsabilização.” Essa nova perspectiva gerencial para o setor público, denominada nova administração pública, busca qualificar o processo de gestão dos recursos públicos. Dessa forma, a LRF constitui-se como um marco regulatório no País.

Assim, esse conjunto de dimensões do qual a receita faz parte passou a ter um certo grau de profissionalismo nas previsões, tanto que a SOF criou uma metodologia para previsão de receitas com base em critérios técnicos, considerando a relevância da gestão pública para a sociedade, no sentido de garantir direitos fundamentais petrificados na Carta Magna de 1988, como serviços de saúde e educação.

De acordo com Santos e Alves (2011), o aumento da eficiência do planejamento e da execução das receitas e despesas municipais contribui para o aumento da capacidade de pagamento das dívidas, equilíbrio do superávit primário e aumento das receitas tributárias. Portanto, a elaboração de previsões orçamentárias adequadas pode favorecer as atividades de planejamento, avaliação, controle e prestação de contas no setor público (ZONATTO; HEIN, 2013).

Dada a importância do planejamento na gestão pública, em especial a previsibilidade da receita, vários estudos nacionais (FIGUEIRÓ, 2002; RUCKERT; 
BORSATTO; RABELO, 2002; CAMPELLO, 2003; SCARPIN; SLOMSKI, 2005; SANTOS; ALVES, 2011; ZONATTO; HEIN, 2013; ZONATTO, RODRIGUES JÚNIOR; TOLEDO FILHO, 2014) e internacionais (MWITA, 2000; GUZMÁN, 2003; GABRIEL et al., 2006) verificaram alguns aspectos relacionados a essa temática. Observa-se nesses estudos que a qualidade da previsibilidade da receita pública é tratada de maneira singular, considerando sua importância na execução dos programas governamentais.

Especificamente sobre a eficiência da previsão orçamentária de receitas públicas, poucas evidências são encontradas na literatura. Da mesma forma, as evidências relatadas por Scarpin e Slomski (2005) e Zonatto e Hein (2013) revelam que nem todos os municípios conseguiram alcançar melhores previsões orçamentárias, mesmo após o advento da LRF, o que pode comprometer as atividades de planejamento, avaliação, controle e accountability no que se refere à arrecadação e aplicação dos recursos públicos.

Nesse contexto, torna-se oportuna a realização de novos estudos com vistas a avaliar a qualidade das previsões orçamentárias dos municípios brasileiros após o advento da LRF. A realização de novos estudos pode revelar a evolução da qualidade das previsões orçamentárias dos municípios brasileiros, bem como a influência da LRF sobre a eficácia de tais previsões. A identificação dos municípios com melhores e piores previsões orçamentárias é capaz de viabilizar a realização de novos estudos, com a finalidade de compreender práticas de gestão orçamentária que podem influenciar a eficácia das previsões realizadas.

Diante do exposto, a partir da realização deste estudo, pretende-se responder à seguinte questão de pesquisa: qual o nível de eficiência e o ranking da previsibilidade da receita orçamentária dos municípios do Estado do Paraná entre os exercícios financeiros de 2002 a 2013? O objetivo neste estudo consistiu em verificar o nível de eficiência e elaborar um ranking da previsibilidade da receita orçamentária dos municípios do Estado do Paraná entre os exercícios financeiros de 2002 a 2013.

Este estudo difere de outros que já abordaram a temática (SCARPIN; SLOMSKI, 2005; ZONATTO; HEIN, 2013), pois além de verificar o nível de eficiência de previsibilidade da receita orçamentária de municípios com características diferentes (outra Unidade de Federação), adiciona um ranking de desempenho em previsibilidade de receita com a utilização da técnica estatística (Technique for Order Preference by Similarity to an Ideal Solution (TOPSIS).

O estudo justifica-se pela relação do tema com questões de interesse público, em que a qualidade da previsão de receita impacta diretamente na eficiência dos 
serviços ofertados à sociedade, em que pese os investimentos (despesas de capital) e as despesas correntes (manutenção) que dependem diretamente de previsibilidade eficiente. O trabalho está estruturado na seguinte ordem: além desta introdução, em seguida apresenta-se o referencial teórico da temática. Na sequência são descritos os procedimentos metodológicos e a análise dos resultados. Por fim, descrevem-se as conclusões do trabalho e as recomendações para a realização de novos estudos.

\section{PREVISIBILIDADE DA RECEITA PÚBLICA}

A receita pública, como fonte de obtenção, é o ingresso de dinheiro nos cofres públicos efetivada de maneira permanente no patrimônio do Estado e não condicionada à sua devolução ou à correspondente baixa patrimonial (REIS; COSTA; SILVEIRA, 2013). O Ministério do Planejamento, Orçamento e Gestão e a Secretaria de Orçamento Federal (2015) assim definem a receita pública:

[...] é a disponibilidade de recursos financeiros que ingressam durante o exercício e constituem elemento novo para o patrimônio público. Instrumento por meio do qual se viabiliza a execução das políticas públicas. A receita orçamentária é fonte de recursos utilizada pelo Estado em programas e ações cuja finalidade precípua é atender às necessidades públicas e demandas da sociedade.

Conforme explica Jund (2008), a conceituação de receita pública pode ser compreendida como todo o recebimento ou ingresso de recursos arrecadados pela entidade para fazer frente às despesas públicas. Esse ingresso de recursos financeiros ao tesouro público é realizado por meio de projeções.

A receita pública classifica-se conforme a categoria econômica em corrente e de capital. A receita corrente refere-se às receitas que provocam efeito positivo no patrimônio líquido do Estado, como, por exemplo, as arrecadações de tributos. Em contraponto, a receita de capital está relacionada àquelas que não provocam efeitos no patrimônio líquido do ente público, simplesmente mudam de local no contexto patrimonial, como o caso das alienações de bens (MINISTÉRIO DO PLANEJAMENTO, ORÇAMENTO E GESTÃO; SECRETARIA DE ORÇAMENTO FEDERAL, 2015).

Além da classificação pela categoria econômica, a receita divide-se também quanto à sua origem, conforme se demostra no Esquema 1. 


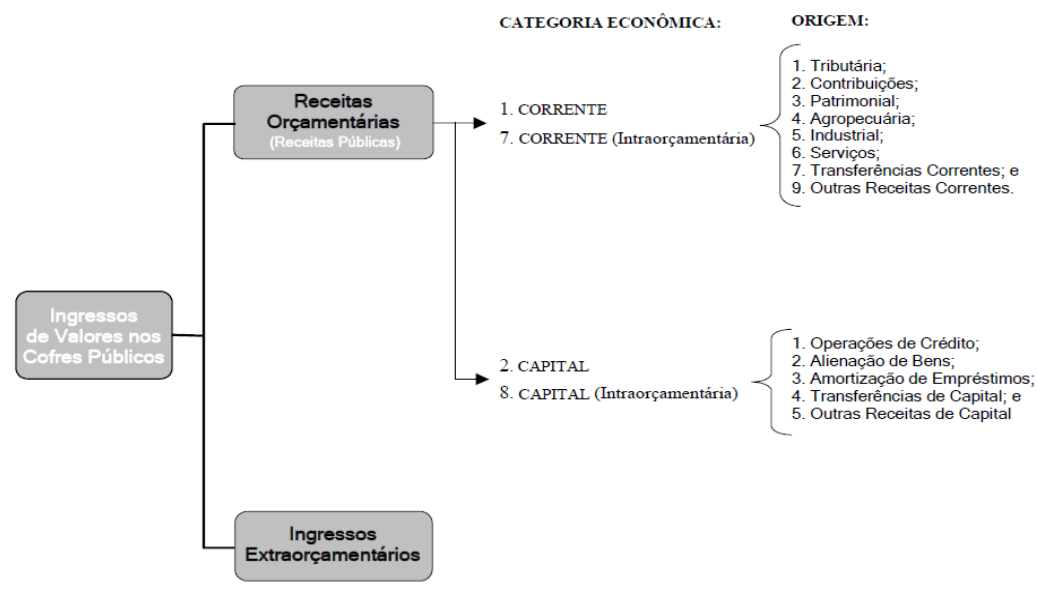

Fonte: Ministério do Planejamento, Orçamento e Gestão e a Secretaria de Orçamento Federal (2015).

A previsibilidade da receita pública obedece a preceitos legais estabelecidos na denominada Lei de Finanças Públicas (Lei n. 4.320, de 17 de março de 1964), a qual aborda no capítulo II as previsões plurianuais e anuais nas peças orçamentárias. De acordo com o estabelecido na referida norma, as previsões orçamentárias devem ser aprovadas pelo Poder Legislativo, ou seja, o tipo de orçamento no Brasil é misto, em que o Poder Executivo elabora e executa e o Legislativo aprova.

Segundo Slomski (2013), a receita pública é aquela prevista na LOA que tenha sido objeto de lei que a estabeleça, em constante observação ao princípio da anterioridade. De maneira geral, o primeiro estágio da receita, de acordo com o manual técnico orçamentário estabelecido pelo Ministério do Planejamento, Orçamento e Gestão e a Secretaria de Orçamento Federal (2015), é a previsão, etapa considerada crucial no processo de planejamento, como se pode evidenciar no Fluxograma 1.

Fluxograma 1 - Etapas da receita orçamentária

Etapaas da Receita Orçamentánia

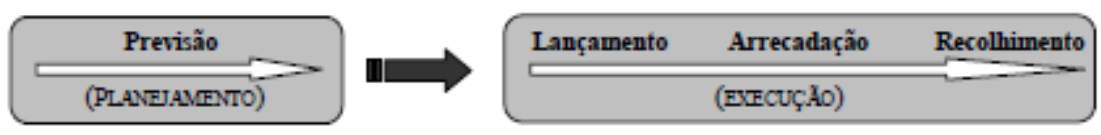

Fonte: Ministério do Planejamento, Orçamento e Gestão e a Secretaria de Orçamento Federal (2015). 
A previsibilidade da receita pública possui papel fundamental no processo orçamentário, sendo um dos requisitos essenciais para atendimento nos pressupostos ditados na legislação de responsabilidade fiscal, correspondendo a um indicador de gestão pública (ROCHA, 2008). Conforme explicam Zonatto e Hein (2013), é a partir de uma previsão orçamentária adequada que se torna possível a qualificação dos processos de planejamento dos recursos necessários para a viabilização de obras públicas, capazes de proporcionar bem-estar comum.

Com o advento da LRF esses processos de planejamento orçamentário ganharam ênfase. O artigo 12 da Lei complementar n. 101 de 04 de maio de 2000, (LRF), preocupa-se com as projeções da receita. Em seu texto expressa o que deve ser observado nas previsões:

Art. 12. As previsões de receita observarão as normas técnicas
e legais, considerarão os efeitos das alterações na legislação,
da variação do índice de preços, do crescimento econômico ou
de qualquer outro fator relevante e serão acompanhadas de de-
monstrativo de sua evolução nos últimos três anos, da projeção
para os dois seguintes àquele a que se referirem, e da metodolo-
gia de cálculo e premissas utilizadas. (BRASIL, 2000).

Apesar da importância da previsibilidade de receitas no setor público, evidências encontradas na literatura sugerem que vários municípios não conseguem alcançar melhores previsões orçamentárias, mesmo após o advento de publicação da LRF (SCARPIN; SLOMSKI, 2005; ZONATTO; HEIN, 2013). Tais constatações revelam falhas nos processos de planejamento desses municípios, em especial nos processos de gestão orçamentária, uma vez que previsões inadequadas podem indicar recursos que não serão realizados ou não serão suficientes para a execução de obras e a realização de investimentos públicos, gerando uma falsa expectativa na população.

A qualidade da previsão orçamentária é essencial para que se possa viabilizar o planejamento das atividades no ente público, garantindo recursos para a manutenção das atividades básicas e a realização de obras e investimentos públicos. Quando a previsão não é eficaz, é necessária a realização de ajustes nas previsões realizadas, o que indica uma necessidade de reavaliação dos planos estabelecidos anteriormente, o que tende a comprometer as atividades de planejamento, avaliação, controle e $a c$ countability no que se refere à arrecadação e aplicação dos recursos públicos, podendo, inclusive, influenciar a manutenção de serviços públicos oferecidos à sociedade. 
A fim de auxiliar os municípios brasileiros a qualificarem suas previsões orçamentárias, bem como atenderem ao disposto no artigo 12 da LRF, a Secretaria de Orçamento Federal desenvolveu um modelo para a previsão de receitas orçamentárias que busca assimilar o comportamento da arrecadação, dado pela seguinte equação:

$$
P_{m}(t)=A_{m}(t-1) \cdot\left(1+E_{p}(t)\right) \cdot\left(1+E_{q}(t)\right) \cdot\left(1+E_{1}(t)\right) \cdot\left(1+E_{s}(t)\right)
$$

Em que:

$\mathrm{P}_{\mathrm{m}}(\mathrm{t})=$ previsão da receita mensal no tempo $\mathrm{t}$;

$\mathrm{A}_{\mathrm{m}}(\mathrm{t}-1)=$ arrecadação mensal da receita para o período anterior;

$\left(1+\mathrm{E}_{\mathrm{p}}(\mathrm{t})\right)=$ variação do efeito preço em $\mathrm{t}$;

$\left(1+\mathrm{E}_{\mathrm{q}}(\mathrm{t})\right)=$ variação do efeito quantidade em $\mathrm{t}$;

$\left(1+\mathrm{E}_{1}(\mathrm{t})\right)=$ variação do efeito legislação em $\mathrm{t}$;

$\left(1+\mathrm{E}_{\varepsilon}(\mathrm{t})\right)=$ variação do erro na previsão.

Esse modelo é utilizado por todos os órgãos da administração pública e esferas de governo, conforme preconiza o manual da Secretaria de Orçamento Federal. Nesse caso, o cálculo prevê um resultado consolidado no qual é aplicado um conjunto de taxas para corrigir os valores e, a partir deste, obtém-se a projeção para o período desejado (MINISTÉRIO DO PLANEJAMENTO, ORÇAMENTO E GESTÃO E A SECRETARIA DE ORÇAMENTO FEDERAL, 2015). Entretanto, o manual deixa obscuro como são obtidas estas taxas adotadas pelo modelo, o que também pode influenciar a qualidade das previsões a serem realizadas pelos municípios.

Considerando que as previsões tendem a ser fortemente influenciadas quando determinadas apenas com base no período anterior da economia, por não observar uma possível sazonalidade no crescimento ou decrescimento econômico do período (ZONATTO; RODRIGUES JÚNIOR; TOLEDO FILHO, 2014), torna-se oportuno avaliar qual o nível de eficiência da previsibilidade da receita orçamentária dos municípios brasileiros em um espaço temporal mais amplo, como no caso proposto neste estudo, a previsão dos municípios do Estado do Paraná pós-advento da LRF. Tais motivações estimularam a realização deste estudo. 


\section{PROCEDIMENTOS METODOLÓGICOS}

A metodologia utilizada na pesquisa é classificada de acordo com os objetivos, os procedimentos e a abordagem do problema. Em relação aos objetivos, esta pesquisa é caracterizada como descritiva, que, segundo Beuren (2008), configura-se como um estudo intermediário entre a pesquisa exploratória e a explicativa, ou seja, não é tão preliminar como a primeira, nem tão aprofundada como a segunda. Nesse contexto, descrever significa identificar, relatar e comparar, entre outros aspectos. Para tanto, propõe-se identificar o nível de eficiência e ranking das previsões da receita dos municípios paranaenses.

Quanto aos procedimentos a pesquisa se caracteriza como documental por utilizar dados publicados (receita prevista e arrecadada dos municípios pesquisados) em fontes secundárias. De acordo com Gil (2007), a pesquisa documental baseia-se em materiais que ainda não receberam um tratamento analítico ou que podem ser elaborados de acordo com os objetivos da pesquisa.

Em relação à abordagem do problema, a pesquisa é caracterizada como quantitativa, que, segundo Creswell (2003), é aquela em que os dados são coletados em instrumento que mensure o objeto observado. As informações coletadas são analisadas com uso de procedimentos estatísticos. Portanto, o estudo aderiu a métodos estatísticos como TOPSIS e análise de clusters para responder à questão de pesquisa.

A população do estudo compreende os municípios do Estado do Paraná. Os dados foram disponibilizados pelo Tribunal de Contas do Estado do Paraná por meio do pedido de acesso à informação n. 177564/2015, correspondente à receita prevista e arrecadada dos 399 munícipios paranaenses no período entre 2002 e 2014. Em razão da insuficiência de informações do ano 2014, esse período foi excluído da análise realizada. Também foram retirados da amostra investigada 16 municípios por falta de dados no período analisado. Assim, a amostra do estudo compreendeu 383 municípios do Estado do Paraná, com informações completas acerca da receita prevista e efetivamente arrecadada no período de 2002 a 2013.

De posse dos dados coletados, inicialmente foram calculadas as diferenças entre a receita prevista e a arrecadada de cada município em todos os períodos analisados. Em seguida, utilizou-se da técnica TOPSIS para ranquear os municípios em desempenho de previsibilidade de receita orçamentária em cada ano do estudo (2002 a 2013). Mediante essas informações, foi possível estabelecer um ranking geral de todos os municípios nesse período, também se utilizando das concepções teóricas estabelecidas pela metodologia TOPSIS. 
A técnica TOPSIS, de acordo com Tzeng e Huang (2011), é um modelo de multicritério que classifica componentes em relação à sua distância com a maior eficiência e a menor eficiência. O resultado do TOPSIS é um número entre zero e um, e a análise procede da seguinte forma: quanto mais próximo de um melhor, ou seja, no caso do presente estudo, municípios que apresentam o resultado do TOPSIS mais próximo de um possuem menor erro percentual de previsibilidade de receitas.

Por fim, para que fosse possível identificar municípios com qualidade similar de previsão de receitas públicas, adotaram-se os procedimentos de análise de clusters, utilizando-se dos resultados da TOPSIS geral descritos anteriormente, por meio do software Statistical Package for the Social Sciences (SPSS), versão 21®, com seis agrupamentos, visto que esse parâmetro de análise de clusters também foi utilizado no estudo desenvolvido por Zonatto e Hein (2013), que investigaram a eficiência da previsibilidade em municípios gaúchos. Os resultados encontrados nesta pesquisa são apresentados a seguir.

\section{ANÁLISE E DISCUSSÃo DOS RESULTADOS}

Direcionada a responder à questão de pesquisa elaborada para a realização deste estudo, a análise e discussão dos resultados foi fragmentada em suas subseções. Inicialmente se procedeu à análise do nível de eficiência da previsibilidade da receita orçamentária dos municípios do Estado do Paraná, considerando-se o ranking de eficiência elaborado nesta pesquisa (TOPSIS). Em sequência, por meio da análise de clusters, efetuou-se a análise dos resultados procurando-se identificar os municípios que alcançaram níveis similares de previsão em todo o período analisado (2002 a 2013).

\subsection{NÍVEIS DE EFICIÊNCIA E RANKING DE PREVISIBILIDADE DA RECEITA ORÇAMENTÁRIA}

Para avaliar os níveis de eficiência das previsões realizadas pelos municípios pesquisados, anteriormente se apurou a acurácia da receita orçamentária, que compreende a diferença entre o valor previsto e o realizado de cada município da amostra (383) e em cada período analisado (2002 a 2013). A seguir, foram transformados os resultados (diferenças) em valores absolutos e calculadas para cada ano a melhor e a pior previsibilidades. Após esse preparo, foram consolidadas as diferenças de cada município e separadas de acordo com a escala intervalar (1-0), obtida a partir da TOPSIS. 
Diante desses resultados (gerados pela TOPSIS), estabeleceram-se 10 escalas, com variação de 0,10 pontos cada (Tabela 1). Na sequência, foram identificados os níveis de eficiência alcançados pelos municípios, sendo eles agrupados conforme as escalas propostas. Os resultados dessa análise são apresentados na Tabela 1.

Tabela 1 - Níveis de eficiência de previsibilidade da receita orçamentária

\begin{tabular}{rrrrr}
\hline $\begin{array}{c}\text { Escala de intervalo } \\
\text { TOPSIS }\end{array}$ & Freq. absol. & Freq. rel. (\%) & Freq. acum. (\%) & \multicolumn{1}{c}{$\begin{array}{c}\text { Posição no } \\
\text { ranking }\end{array}$} \\
\hline 1,00 a 0,91 & 99 & $25,85 \%$ & $25,85 \%$ & $1^{\circ}$ a $99^{\circ}$ \\
0,90 a 0,81 & 245 & $63,97 \%$ & $89,82 \%$ & $100^{\circ}$ a $344^{\circ}$ \\
0,80 a 0,71 & 34 & $8,88 \%$ & $98,70 \%$ & $345^{\circ}$ a $378^{\circ}$ \\
0,70 a 0,61 & 3 & $0,78 \%$ & $99,48 \%$ & $379^{\circ}$ a $381^{\circ}$ \\
060, a 0,51 & 1 & $0,26 \%$ & $99,74 \%$ & $382^{\circ}$ \\
050, a 0,41 & 1 & $0,26 \%$ & $100 \%$ & $383^{\circ}$ \\
TOTAL & 383 & $100 \%$ & & \\
\hline
\end{tabular}

Fonte: os autores.

Como se pode verificar na Tabela 1, os 383 municípios pesquisados alcançaram índices de eficiência que variam entre as escalas 0,41 e 1,00, visto que 99 municípios (25,85\%) podem ser considerados os mais eficientes do período, alcançando níveis de eficiência superiores a 0,91. De maneira geral, constata-se que, no período analisado, a maioria dos munícipios do Estado do Paraná (89,82\%) apresentou altos índices de eficiência (entre 0,81 e 1,00) da previsibilidade de receitas orçamentárias.

Considerando-se o intervalo real encontrado na pesquisa, os 100 primeiros municípios em nível de eficiência alcançaram índice máximo de 0,9536 (1º ) mínimo de $0,9099\left(100^{\circ}\right)$. Os municípios que ficaram entre o $101^{\circ}$ e o $200^{\circ}$ lugares alcançaram índices mínimos de eficiência de 0,9093 $\left(101^{\circ}\right)$ e máximos de 0,8875 (200). Já os municípios que foram classificados entre o $201^{\circ}$ e o $300^{\circ}$ lugares alcançaram indicadores de eficiência mínimos de 0,8874 (201º e máximos de 0,8558 (300º). O menor nível de eficiência alcançado por um município pesquisado foi de 0,4213 (383).

A Tabela 2 evidencia o ranking com a identificação dos 10 melhores municípios em previsibilidade de receita orçamentária, dos 10 municípios que possuem previsibilidade intermediária e dos 10 munícipios que apresentam a menor eficiência em previsibilidade de receita orçamentária no período analisado. 
Tabela 2 - Ranking do desempenho de municípios paranaenses em previsibilidade orçamentária

\begin{tabular}{|c|c|c|c|c|c|c|c|c|}
\hline \multicolumn{3}{|c|}{10 mais eficientes } & \multicolumn{3}{|c|}{10 intermediários } & \multicolumn{3}{|c|}{10 menos eficientes } \\
\hline $\begin{array}{l}\text { TOP- } \\
\text { SIS }\end{array}$ & Rank. & Mun. & $\begin{array}{l}\text { TOP- } \\
\text { SIS }\end{array}$ & Rank. & Mun. & $\begin{array}{l}\text { TOP- } \\
\text { SIS }\end{array}$ & Rank. & Mun. \\
\hline 0,95 & $1^{\circ}$ & Guaporema & 0,89 & $186^{\circ}$ & Goioxim & 0,72 & $374^{\circ}$ & Amaporã \\
\hline 0,95 & $2^{\circ}$ & Altônia & 0,89 & $187^{\circ}$ & $\begin{array}{l}\text { Itaúna do } \\
\text { Sul }\end{array}$ & 0,72 & $375^{\circ}$ & $\begin{array}{l}\text { Nova A. do } \\
\text { Ivaí }\end{array}$ \\
\hline 0,95 & $3^{\circ}$ & Rio Negro & 0,89 & $188^{\circ}$ & Ourizona & 0,72 & $376^{\circ}$ & Braganey \\
\hline 0,95 & $4^{\circ}$ & $\begin{array}{l}\text { Rancho } \\
\text { Alegre }\end{array}$ & 0,89 & $189^{\circ}$ & Japurá & 0,71 & $377^{\circ}$ & Mirador \\
\hline 0,95 & $5^{\circ}$ & Faxinal & 0,89 & $190^{\circ}$ & Fênix & 0,71 & $378^{\circ}$ & Cambira \\
\hline 0,94 & $6^{\circ}$ & $\begin{array}{l}\text { Barra do } \\
\text { Jacaré }\end{array}$ & 0,89 & $191^{\circ}$ & Sabáudia & 0,70 & $379^{\circ}$ & $\begin{array}{l}\text { Agudos do } \\
\text { Sul }\end{array}$ \\
\hline 0,94 & $7^{\circ}$ & Apucarana & 0,89 & $192^{\circ}$ & Ortigueira & 0,69 & $380^{\circ}$ & $\begin{array}{l}\text { Moreira } \\
\text { Sales }\end{array}$ \\
\hline 0,94 & $8^{\circ}$ & Maringá & 0,89 & $193^{\circ}$ & Sengés & 0,66 & $381^{\circ}$ & $\begin{array}{l}\text { Renas- } \\
\text { cença }\end{array}$ \\
\hline 0,94 & $9^{\circ}$ & $\begin{array}{l}\text { Franc. } \\
\text { Beltrão }\end{array}$ & 0,89 & $194^{\circ}$ & Tomazina & 0,54 & $382^{\circ}$ & $\begin{array}{l}\text { Nova } \\
\text { Olímpia }\end{array}$ \\
\hline 0,94 & $10^{\circ}$ & Curitiba & 0,89 & $195^{\circ}$ & $\begin{array}{l}\text { Guara- } \\
\text { niaçu }\end{array}$ & 0,42 & $383^{\circ}$ & Palmas \\
\hline & & {$[\ldots]$} & & & {$[\ldots]$} & & & {$[\ldots]$} \\
\hline
\end{tabular}

Nota-se que, dos 10 melhores municípios do ranking apresentado na Tabela 2, apenas dois estão listados entre os municípios com maior população do Estado do Paraná ( $8^{\circ}$ Maringá e $10^{\circ}$ Curitiba). Os seis primeiros lugares no ranking elaborado ( $1^{\circ}$ Guaporema, $2^{\circ}$ Altônia, $3^{\circ}$ Rio Negro, $4^{\circ}$ Rancho Alegre, $5^{\circ}$ Faxinal e $6^{\circ}$ Barra do Jacaré) são ocupados por municípios que possuem entre 2.000 e 35.000 habitantes, sugerindo, então, que a melhor previsibilidade independe da quantidade populacional do município.

Em relação aos 10 municípios intermediários (186º Goioxim, $187^{\circ}$ Itaúna do Sul, $188^{\circ}$ Ourizona, $189^{\circ}$ Japurá, $190^{\circ}$ Fênix, $191^{\circ}$ Sabáudia, $192^{\circ}$ Ortigueira, $193^{\circ}$ Sengés, $194^{\circ}$ Tomazina e $195^{\circ}$ Guaraniaçu) e aos 10 municípios com piores previsões no período (383 ${ }^{\circ}$ Palmas, $382^{\circ}$ Nova Olímpia, $381^{\circ}$ Renascença, $380^{\circ}$ Moreira Sales, $379^{\circ}$ Agudos do Sul, $378^{\circ}$ Cambira, $377^{\circ}$ Mirador, 376 Braganey, 375 Nova Aliança do Ivaí e $374^{\circ}$ Amaporã), percebe-se que todos são de pequeno porte, com população inferior a 40.000 habitantes.

Os resultados encontrados nessa etapa da pesquisa revelam que o advento da Lei de Responsabilidade Fiscal pode ter contribuído para a qualidade da previsão 
orçamentária realizada pelos municípios pesquisados, uma vez que a maioria desses municípios apresentou bons indicadores de eficiência no que se refere à previsibilidade de receitas. Da mesma forma, constatou-se que a variação identificada entre os municípios pesquisados é mais harmônica, visto que 300 municípios foram classificados com índice de eficiência variante entre 0,85 e 0,95.

O estabelecimento de previsões orçamentárias mais eficientes tem sido abordado na literatura como uma necessidade para a qualificação dos processos de gestão pública (SCARPIN; SLOMSKI, 2005; ZONATTO; HEIN, 2013). A melhor previsibilidade de receitas oportuniza ao gestor a realização de um planejamento mais adequado para a realização de investimentos e obras públicas, sem que haja comprometimento da qualidade dos demais serviços prestados à população. Em contrapartida, previsões ineficientes tendem a levantar incertezas quanto à real capacidade de investimentos do município.

Apesar de a maioria dos municípios pesquisados alcançar bons índices de eficiência, os resultados encontrados também revelam que determinados municípios não apresentaram, nesse período, previsões orçamentárias eficientes. Esses resultados revelam a necessidade de melhoria nos processos de previsibilidade dessas entidades. Previsões inadequadas podem induzir a decisões incorretas, as quais podem inviabilizar o desenvolvimento de obras, a realização de investimentos e a manutenção de serviços públicos.

Portanto, torna-se necessária a qualificação dos processos de previsibilidade nesses municípios. Assim, a identificação de municípios com maior eficiência permite a troca de experiências e conhecimentos em práticas de gestão orçamentária, as quais podem proporcionar melhores previsões de receitas, o que pode favorecer o desenvolvimento das atividades de gestão na esfera pública.

\subsection{NÍVEIS DE SIMILARIDADE DE EFICIÊNCIA DE PREVISIBILIDADE DA RECEITA ORÇAMENTÁRIA}

Realizada a análise do nível de eficiência da previsibilidade da receita orçamentária dos municípios pesquisados, a seguir, utilizando a técnica de análise de clusters, efetuou-se o agrupamento dos municípios com previsões similares, considerando-se os resultados alcançados em todo o período analisado (2002 a 2013). A Tabela 3 evidencia os seis clusters formados com as respectivas quantidades de munícipios que compõem cada agrupamento. 


\begin{tabular}{lrr}
\hline & 1 & 1,000 \\
& 3 & 47,000 \\
Cluster & 4 & 16,000 \\
& 5 & 184,000 \\
& 6 & 1,000 \\
Válido & & 384,000 \\
Ausente & &, 000 \\
\hline Fonte: os autores. & &
\end{tabular}

De acordo com os resultados apresentados na Tabela 3, observa-se que os clusters 1 e 5 são formados por um único município, sendo os clusters 4 e 6 aqueles que agruparam a maior parte da amostra pesquisada, com 184 e 134 municípios, respectivamente. Analisou-se em ordem crescente o número de casos de cada agrupamento. Assim, na sequência (Tabela 4), são apresentados os resultados encontrados para a análise dos clusters 1 e 5.

Tabela 4 - Clusters 1 e 5 (TOPSIS e Ranking)

\begin{tabular}{llllll}
\hline \multicolumn{2}{c}{ Cluster 1 } & \multicolumn{3}{c}{ Cluster 5 } \\
\hline TOPSIS & RANK. & MUN. & TOPSIS & RANK. & MUN. \\
0,54 & $382^{\circ}$ & Nova Olímpia & 0,42 & $383^{\circ}$ & Palmas \\
\hline
\end{tabular}

Fonte: os autores.

Na análise da Tabela 4, percebe-se que tanto no cluster 1 quanto no 5 foi agrupado somente um município para cada bloco. Os resultados mostram que os municípios desses clusters são Nova Olímpia e Palmas, os quais estão nos últimos lugares da classificação realizada a partir do ranking TOPSIS $\left(382^{\circ}\right.$ e $\left.383^{\circ}\right)$. Portanto, esses clusters (1 e 5) são os que agruparam os municípios com pior eficiência em previsibilidade de receita orçamentária. Na sequência, a Tabela 5 evidencia os casos agrupados no cluster 3 . 
Tabela 5 - Cluster 3 (TOPSIS e Ranking) - do $366^{\circ}$ ao $381^{\circ}$ lugar

\begin{tabular}{|c|c|c|c|c|c|c|c|c|}
\hline $\begin{array}{l}\text { TOP- } \\
\text { SIS }\end{array}$ & Rank. & Mun. & $\begin{array}{l}\text { TOP- } \\
\text { SIS }\end{array}$ & Rank. & Mun. & $\begin{array}{l}\text { TOP- } \\
\text { SIS }\end{array}$ & Rank. & Mun. \\
\hline 0,77 & $366^{\circ}$ & $\begin{array}{l}\text { Campina Da } \\
\text { Lagoa }\end{array}$ & 0,75 & $372^{\circ}$ & $\begin{array}{l}\text { Janió- } \\
\text { polis }\end{array}$ & 0,71 & $378^{\circ}$ & Cambira \\
\hline 0,76 & $367^{\circ}$ & $\begin{array}{l}\text { Campo } \\
\text { Bonito }\end{array}$ & 0,74 & $373^{\circ}$ & $\begin{array}{l}\text { Rancho } \\
\text { Alegre d' } \\
\text { Oeste }\end{array}$ & 0,70 & $379^{\circ}$ & $\begin{array}{l}\text { Agudos } \\
\text { do Sul }\end{array}$ \\
\hline 0,76 & $368^{\circ}$ & $\begin{array}{l}\text { Iracema do } \\
\text { Oeste }\end{array}$ & 0,72 & $374^{\circ}$ & Amaporã & 0,69 & $380^{\circ}$ & $\begin{array}{l}\text { Moreira } \\
\text { Sales }\end{array}$ \\
\hline 0,76 & $369^{\circ}$ & $\begin{array}{l}\text { Santo Ant. } \\
\text { do Caiuá }\end{array}$ & 0,72 & $375^{\circ}$ & $\begin{array}{l}\text { Nova A. } \\
\text { do Ivaí }\end{array}$ & 0,66 & $381^{\circ}$ & $\begin{array}{l}\text { Renas- } \\
\text { cença }\end{array}$ \\
\hline 0,75 & $370^{\circ}$ & Piraí do Sul & 0,72 & $376^{\circ}$ & Braganey & & & \\
\hline 0,75 & $371^{\circ}$ & Iretama & 0,71 & $377^{\circ}$ & Mirador & & & \\
\hline
\end{tabular}

Fonte: os autores.

O agrupamento que formou o cluster 3 é composto por 16 municípios, referindo-se ainda àquele grupo de municípios que apresentou as últimas colocações no ranking do TOPSIS (Tabela 5), ocupando a posição entre o 366º o $381^{\circ}$ lugares. Esses resultados revelam, também, uma previsibilidade de receitas deficiente nesse período. A Tabela 6 evidencia os municípios que formam o cluster 2.

Tabela 5 - Cluster 2 (TOPSIS e Ranking) - do $319^{\circ}$ aa $365^{\circ}$ lugar

\begin{tabular}{|c|c|c|c|c|c|c|c|c|}
\hline $\begin{array}{c}\text { TOP- } \\
\text { SIS }\end{array}$ & Rank. & Mun. & $\begin{array}{c}\text { TOP- } \\
\text { SIS }\end{array}$ & Rank. & Mun. & $\begin{array}{c}\text { TOP- } \\
\text { SIS }\end{array}$ & Rank. & Mun. \\
\hline 0,84 & $319^{\circ}$ & Tapejara & 0,82 & $335^{\circ}$ & Vitorino & 0,80 & $351^{\circ}$ & Floraí \\
\hline 0,84 & $320^{\circ}$ & Floresta & 0,82 & $336^{\circ}$ & Uniflor & 0,80 & $352^{\circ}$ & $\begin{array}{l}\text { São José } \\
\text { das Pal- } \\
\text { meiras }\end{array}$ \\
\hline 0,84 & $321^{\circ}$ & Peabiru & 0,82 & $337^{\circ}$ & Carambeí & 0,80 & $353^{\circ}$ & $\begin{array}{l}\text { Rio Bran- } \\
\text { co do Sul }\end{array}$ \\
\hline 0,84 & $322^{\circ}$ & $\begin{array}{l}\text { Planaltina } \\
\text { do Paraná }\end{array}$ & 0,82 & $338^{\circ}$ & $\begin{array}{l}\text { Almirante } \\
\text { Tamandaré }\end{array}$ & 0,79 & $354^{\circ}$ & Sertaneja \\
\hline 0,84 & $323^{\circ}$ & $\begin{array}{l}\text { Ariranha } \\
\text { do Ivaí }\end{array}$ & 0,82 & $339^{\circ}$ & Jesuítas & 0,79 & $355^{\circ}$ & $\begin{array}{l}\text { Munhoz } \\
\text { de Mello }\end{array}$ \\
\hline 0,83 & $324^{\circ}$ & Sulina & 0,82 & $340^{\circ}$ & Porto Rico & 0,79 & $356^{\circ}$ & Céu Azul \\
\hline 0,83 & $325^{\circ}$ & $\begin{array}{l}\text { Esperança } \\
\text { Nova }\end{array}$ & 0,82 & $341^{\circ}$ & Ângulo & 0,79 & $357^{\circ}$ & $\begin{array}{l}\text { Quarto } \\
\text { Centená- } \\
\text { rio }\end{array}$ \\
\hline 0,83 & $326^{\circ}$ & $\begin{array}{l}\text { Coronel } \\
\text { Domingos } \\
\text { Soares } \\
\text { Fazenda }\end{array}$ & 0,82 & $342^{\circ}$ & $\begin{array}{l}\text { Brasilândia } \\
\text { do Sul }\end{array}$ & 0,79 & $358^{\circ}$ & Anahy \\
\hline 0,83 & $327^{\circ}$ & $\begin{array}{l}\text { Rio Gran- } \\
\text { de }\end{array}$ & 0,81 & $343^{\circ}$ & Florestópolis & 0,79 & $359^{\circ}$ & Mariluz \\
\hline 0,83 & $328^{\circ}$ & Piraquara & 0,81 & $344^{\circ}$ & Adrianópolis & 0,78 & $360^{\circ}$ & Jussara \\
\hline 0,83 & $329^{\circ}$ & Goioerê & 0,81 & $345^{\circ}$ & $\begin{array}{l}\text { Formosa do } \\
\text { Oeste }\end{array}$ & 0,78 & $361^{\circ}$ & $\begin{array}{l}\text { Reserva } \\
\text { do Iguaçu }\end{array}$ \\
\hline
\end{tabular}




\begin{tabular}{|c|c|c|c|c|c|c|c|c|}
\hline $\begin{array}{c}\text { TOP- } \\
\text { SIS }\end{array}$ & Rank. & Mun. & $\begin{array}{c}\text { TOP- } \\
\text { SIS }\end{array}$ & Rank. & Mun. & $\begin{array}{c}\text { TOP- } \\
\text { SIS }\end{array}$ & Rank. & Mun. \\
\hline 0,83 & $330^{\circ}$ & $\begin{array}{l}\text { Coronel } \\
\text { Vivida }\end{array}$ & 0,81 & $346^{\circ}$ & Pien & 0,78 & $362^{\circ}$ & $\begin{array}{l}\text { São } \\
\text { Pedro do }\end{array}$ \\
\hline 0,83 & $331^{\circ}$ & Pinhalão & 0,80 & $347^{\circ}$ & $\begin{array}{l}\text { Honório } \\
\text { Serpa }\end{array}$ & 0,78 & $363^{\circ}$ & $\begin{array}{l}\text { Santá } \\
\text { Inês }\end{array}$ \\
\hline 0,82 & $332^{\circ}$ & Xambrê & 0,80 & $348^{\circ}$ & Quitandinha & 0,77 & $364^{\circ}$ & Marialva \\
\hline 0,82 & $333^{\circ}$ & $\begin{array}{l}\text { Prado } \\
\text { Ferreira }\end{array}$ & 0,80 & $349^{\circ}$ & Paranacity & 0,77 & $365^{\circ}$ & Iguatu \\
\hline 0,82 & $334^{\circ}$ & $\begin{array}{l}\text { Cornélio } \\
\text { Procópio }\end{array}$ & 0,80 & $350^{\circ}$ & Guapirama & & & \\
\hline
\end{tabular}

Como se pode verificar na Tabela 6, o cluster 2 é formado por um conjunto de 47 municípios, os quais também estão listados entre as últimas colocações no ranking elaborado nesta pesquisa, sendo mais especificamente entre o $319^{\circ}$ e o $365^{\circ}$ lugares. Logo, infere-se que esse grupo de municípios também apresentou anomalias na previsão de receitas nesse período, visto que o resultado do índice de eficiência (TOPSIS) estabelecido para esse grupo variou entre 0,77 e 0,84. A Tabela 7 evidencia os resultados encontrados para a formação do cluster 6, correspondente ao segundo maior agrupamento formado nesta pesquisa (134 casos).

Tabela 7 - Cluster 6 (TOPSIS e Ranking) - do $185^{\circ}$ ao $318^{\circ}$ lugar

\begin{tabular}{|c|c|c|c|c|c|c|c|c|}
\hline $\begin{array}{l}\text { TOP- } \\
\text { SIS }\end{array}$ & Rank. & Mun. & $\begin{array}{l}\text { TOP- } \\
\text { SIS }\end{array}$ & Rank. & Mun. & $\begin{array}{l}\text { TOP- } \\
\text { SIS }\end{array}$ & Rank. & Mun. \\
\hline 0,89 & $185^{\circ}$ & $\begin{array}{l}\text { Marme- } \\
\text { leiro }\end{array}$ & 0,88 & $242^{\circ}$ & Mariópolis & 0,86 & $299^{\circ}$ & Tupãssi \\
\hline 0,89 & $186^{\circ}$ & Goioxim & 0,88 & $243^{\circ}$ & $\begin{array}{l}\text { Indianó- } \\
\text { polis }\end{array}$ & 0,86 & $300^{\circ}$ & \multirow{2}{*}{$\begin{array}{l}\text { Tunas do } \\
\text { Paraná } \\
\text { Nossa Se- } \\
\text { nhora das } \\
\text { Graças }\end{array}$} \\
\hline 0,89 & $187^{\circ}$ & $\begin{array}{l}\text { Itaúna do } \\
\text { Sul }\end{array}$ & 0,88 & $244^{\circ}$ & $\begin{array}{l}\text { Ouro Verde } \\
\text { do Oeste }\end{array}$ & 0,86 & $301^{\circ}$ & \\
\hline 0,89 & $188^{\circ}$ & Ourizona & 0,87 & $245^{\circ}$ & $\begin{array}{l}\text { Siqueira } \\
\text { Campos }\end{array}$ & 0,86 & $302^{\circ}$ & Mandaguari \\
\hline 0,89 & $189^{\circ}$ & Japurá & 0,87 & $246^{\circ}$ & Santa Fé & 0,86 & $303^{\circ}$ & Imbituva \\
\hline 0,89 & $190^{\circ}$ & Fênix & 0,87 & $247^{\circ}$ & $\begin{array}{l}\text { Wenceslau } \\
\text { Braz }\end{array}$ & 0,86 & $304^{\circ}$ & $\begin{array}{l}\text { Cidade Gaú- } \\
\text { cha }\end{array}$ \\
\hline 0,89 & $191^{\circ}$ & Sabáudia & 0,87 & $248^{\circ}$ & $\begin{array}{l}\text { Manfrinó- } \\
\text {-polis }\end{array}$ & 0,85 & $305^{\circ}$ & Paula Freitas \\
\hline 0,89 & $192^{\circ}$ & Ortigueira & 0,87 & $249^{\circ}$ & Itaipulândia & 0,85 & $306^{\circ}$ & $\begin{array}{l}\text { Mangueiri- } \\
\text {-nha }\end{array}$ \\
\hline 0,89 & $193^{\circ}$ & Sengés & 0,87 & $250^{\circ}$ & Rio Azul & 0,85 & $307^{\circ}$ & $\begin{array}{l}\text { Santo Ant. da } \\
\text { Platina }\end{array}$ \\
\hline 0,89 & $194^{\circ}$ & Tomazina & 0,87 & $251^{\circ}$ & Paiçandu & 0,85 & $308^{\circ}$ & Assaí \\
\hline 0,89 & $195^{\circ}$ & $\begin{array}{l}\text { Guara- } \\
\text { niaçu }\end{array}$ & 0,87 & $252^{\circ}$ & $\begin{array}{l}\text { São José da } \\
\text { Boa Vista }\end{array}$ & 0,85 & $309^{\circ}$ & $\begin{array}{l}\text { Santa Isabel } \\
\text { do Ivaí }\end{array}$ \\
\hline
\end{tabular}




\begin{tabular}{|c|c|c|c|c|c|c|c|c|}
\hline $\begin{array}{l}\text { TOP- } \\
\text { SIS }\end{array}$ & Rank. & Mun. & $\begin{array}{l}\text { TOP- } \\
\text { SIS }\end{array}$ & Rank. & Mun. & $\begin{array}{l}\text { TOP- } \\
\text { SIS }\end{array}$ & Rank. & Mun. \\
\hline 0,89 & $196^{\circ}$ & $\begin{array}{l}\text { Alto } \\
\text { Piquiri }\end{array}$ & 0,87 & $253^{\circ}$ & $\begin{array}{l}\text { Barbosa } \\
\text { Ferraz }\end{array}$ & 0,85 & $310^{\circ}$ & Marilena \\
\hline 0,89 & $197^{\circ}$ & $\begin{array}{l}\text { Corumba- } \\
\text { taí do Sul }\end{array}$ & 0,87 & $254^{\circ}$ & $\begin{array}{l}\text { Vera Cruz } \\
\text { do Oeste }\end{array}$ & 0,85 & $311^{\circ}$ & Lidianópolis \\
\hline 0,89 & $198^{\circ}$ & $\begin{array}{l}\text { Boa Vista } \\
\text { da Apare- } \\
\text { cida }\end{array}$ & 0,87 & $255^{\circ}$ & $\begin{array}{l}\text { Nova Santa } \\
\text { Bárbara }\end{array}$ & 0,85 & $312^{\circ}$ & Irati \\
\hline 0,89 & $199^{\circ}$ & Palmeira & 0,87 & $256^{\circ}$ & Japira & 0,85 & $313^{\circ}$ & $\begin{array}{l}\text { Campina do } \\
\text { Simão }\end{array}$ \\
\hline 0,89 & $200^{\circ}$ & Colombo & 0,87 & $257^{\circ}$ & Cascavel & 0,84 & $314^{\circ}$ & Nova Fátima \\
\hline 0,89 & $201^{\circ}$ & $\begin{array}{l}\text { Congonhi- } \\
\text {-nhas }\end{array}$ & 0,87 & $258^{\circ}$ & Leópolis & 0,84 & $315^{\circ}$ & Mandirituba \\
\hline 0,89 & $202^{\circ}$ & $\begin{array}{l}\text { Telêmaco } \\
\text { Borba }\end{array}$ & 0,87 & $259^{\circ}$ & $\begin{array}{l}\text { Assis Cha- } \\
\text { teau-briand }\end{array}$ & 0,84 & $316^{\circ}$ & Califórnia \\
\hline 0,89 & $203^{\circ}$ & $\begin{array}{l}\text { Francisco } \\
\text { Alves }\end{array}$ & 0,87 & $260^{\circ}$ & $\begin{array}{l}\text { Campo } \\
\text { Largo }\end{array}$ & 0,84 & $317^{\circ}$ & $\begin{array}{l}\text { Quinta do } \\
\text { Sol }\end{array}$ \\
\hline 0,89 & $204^{\circ}$ & $\begin{array}{l}\text { Diamante } \\
\text { do Norte }\end{array}$ & 0,87 & $261^{\circ}$ & Miraselva & 0,84 & $318^{\circ}$ & Ampére \\
\hline \multicolumn{3}{|c|}{20 mais eficientes - Cluster 6} & \multicolumn{3}{|c|}{20 intermediários - Cluster 6} & \multirow{2}{*}{\multicolumn{3}{|c|}{20 menos eficientes - Cluster 6}} \\
\hline \multicolumn{3}{|c|}{ [...] posição $205^{\circ}$ a $241^{\circ}$} & \multicolumn{3}{|c|}{ [...] posição $262^{\circ}$ a $298^{\circ}$} & & & \\
\hline
\end{tabular}

Fonte: os autores.

O cluster 6 foi o agrupamento formado pelos municípios que alcançaram as colocações entre o $185^{\circ}$ e o $318^{\circ}$ lugares. Esses municípios formam um grupo intermediário, que alcançou boas previsões no período, porém, não as melhores. O resultado da TOPSIS encontrado nesse agrupamento sinaliza que esses municípios alcançaram índices de eficiência que variam entre 0,84 e 0,89, valores mais próximos de 1,0, comparativamente aos municípios que formam os clusters 1, 2, 3 e 5 . Esses resultados revelam uma eficiência de previsibilidade intermediária, considerando todos os municípios analisados. O cluster 4 é o último a ser analisado, o qual apresenta os municípios que alcançaram melhor eficiência em suas previsões (Tabela 8).

Tabela 8 - Cluster 4 (TOPSIS e Ranking) - do $1^{\circ}$ ao $184^{\circ}$ lugar

\begin{tabular}{|c|c|c|c|c|c|c|c|c|}
\hline $\begin{array}{l}\text { TOP- } \\
\text { SIS }\end{array}$ & Rank. & Mun. & $\begin{array}{l}\text { TOP- } \\
\text { SIS }\end{array}$ & Rank. & Mun. & $\begin{array}{l}\text { TOP- } \\
\text { SIS }\end{array}$ & Rank. & Mun. \\
\hline 0,95 & $1^{o}$ & $\begin{array}{l}\text { Guapore- } \\
\text { ma }\end{array}$ & 0,91 & $83^{\circ}$ & Tibagi & 0,90 & $165^{\circ}$ & Guaratuba \\
\hline 0,95 & $2^{\circ}$ & Altonia & 0,91 & $84^{\circ}$ & $\begin{array}{l}\text { Anta } \\
\text { Lúcia }\end{array}$ & 0,90 & $166^{\circ}$ & Imbaú \\
\hline 0,95 & $3^{\circ}$ & $\begin{array}{l}\text { Rio } \\
\text { Negro }\end{array}$ & 0,91 & $85^{\circ}$ & Lapa & 0,90 & $167^{\circ}$ & Sarandi \\
\hline 0,95 & $4^{\circ}$ & $\begin{array}{l}\text { Rancho } \\
\text { Alegre }\end{array}$ & 0,91 & $86^{\circ}$ & 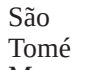 & 0,90 & $168^{\circ}$ & Pitanga \\
\hline 0,95 & $5^{o}$ & Faxinal & 0,91 & $87^{\circ}$ & $\begin{array}{l}\text { Merce- } \\
\text { des }\end{array}$ & 0,90 & $169^{\circ}$ & Nova Cantu \\
\hline
\end{tabular}




\begin{tabular}{|c|c|c|c|c|c|c|c|c|}
\hline $\begin{array}{l}\text { TOP- } \\
\text { SIS }\end{array}$ & Rank. & Mun. & $\begin{array}{l}\text { TOP- } \\
\text { SIS }\end{array}$ & Rank. & Mun. & $\begin{array}{l}\text { TOP- } \\
\text { SIS }\end{array}$ & Rank. & Mun. \\
\hline 0,94 & $6^{\circ}$ & $\begin{array}{l}\text { Barra do } \\
\text { Jacaré }\end{array}$ & 0,91 & $88^{\circ}$ & $\begin{array}{l}\text { Pato } \\
\text { Branco } \\
\text { Fer- }\end{array}$ & 0,90 & $170^{\circ}$ & Araucária \\
\hline 0,94 & $7^{\circ}$ & $\begin{array}{l}\text { Apuca- } \\
\text { rana }\end{array}$ & 0,91 & $89^{\circ}$ & $\begin{array}{l}\text { nandes } \\
\text { Pinhei- } \\
\text { ro }\end{array}$ & 0,90 & $171^{\circ}$ & Marumbi \\
\hline 0,94 & $8^{\circ}$ & Maringá & 0,91 & $90^{\circ}$ & $\begin{array}{l}\text { Campo } \\
\text { Mourão }\end{array}$ & 0,90 & $172^{\circ}$ & $\begin{array}{l}\text { Santo Antonio } \\
\text { do Sudoeste }\end{array}$ \\
\hline 0,94 & $9^{\circ}$ & $\begin{array}{l}\text { Francis- } \\
\text { co Bel- } \\
\text { trão }\end{array}$ & 0,91 & $91^{\circ}$ & Itaguajé & 0,90 & $173^{\circ}$ & Bituruna \\
\hline 0,94 & $10^{\circ}$ & Curitiba & 0,91 & $92^{\circ}$ & $\begin{array}{l}\text { São } \\
\text { Jorge } \\
\text { do } \\
\text { Patrocí- } \\
\text { nio } \\
\text { Entre }\end{array}$ & 0,90 & $174^{\circ}$ & Bandeirantes \\
\hline 0,94 & $11^{\circ}$ & Corbélia & 0,91 & $93^{\circ}$ & $\begin{array}{l}\text { Rios do } \\
\text { Oeste }\end{array}$ & 0,90 & $175^{\circ}$ & Marquinho \\
\hline 0,94 & $12^{\circ}$ & $\begin{array}{l}\text { Querên- } \\
\text { cia do } \\
\text { Norte }\end{array}$ & 0,91 & $94^{\circ}$ & $\begin{array}{l}\text { Bela } \\
\text { Vista } \\
\text { do } \\
\text { Paraíso }\end{array}$ & 0,89 & $176^{\circ}$ & Rio Bom \\
\hline 0,94 & $13^{\circ}$ & $\begin{array}{l}\text { Antonio } \\
\text { Olinto }\end{array}$ & 0,91 & $95^{\circ}$ & $\begin{array}{l}\text { Guami- } \\
\text { ranga } \\
\text { Pato }\end{array}$ & 0,89 & $177^{\circ}$ & Jardim Alegre \\
\hline 0,94 & $14^{\circ}$ & $\begin{array}{l}\text { Andirá } \\
\text { Nova }\end{array}$ & 0,91 & $96^{\circ}$ & $\begin{array}{l}\text { Braga- } \\
\text { do }\end{array}$ & 0,89 & $178^{\circ}$ & $\begin{array}{l}\text { Alvorada do } \\
\text { Sul }\end{array}$ \\
\hline 0,94 & $15^{\circ}$ & $\begin{array}{l}\text { Santa } \\
\text { Rosa }\end{array}$ & 0,91 & $97^{\circ}$ & Rondon & 0,89 & $179^{\circ}$ & Realeza \\
\hline 0,94 & $16^{\circ}$ & $\begin{array}{l}\text { Porto } \\
\text { Vitória }\end{array}$ & 0,91 & $98^{\circ}$ & $\begin{array}{l}\text { Ivai- } \\
\text { porã }\end{array}$ & 0,89 & $180^{\circ}$ & $\begin{array}{l}\text { Diamante do } \\
\text { Oeste }\end{array}$ \\
\hline 0,94 & $17^{\circ}$ & $\begin{array}{l}\text { Pitan- } \\
\text { gueiras }\end{array}$ & 0,91 & $99^{\circ}$ & $\begin{array}{l}\text { Media- } \\
\text { neira }\end{array}$ & 0,89 & $181^{\circ}$ & $\begin{array}{l}\text { Godoy Mo- } \\
\text { reira }\end{array}$ \\
\hline 0,93 & $18^{\circ}$ & $\begin{array}{l}\text { Enge- } \\
\text { nheiro } \\
\text { Beltrão }\end{array}$ & 0,91 & $100^{\circ}$ & $\begin{array}{l}\text { Ronca- } \\
\text { dor }\end{array}$ & 0,89 & $182^{\circ}$ & $\begin{array}{l}\text { Bocaiúva do } \\
\text { Sul }\end{array}$ \\
\hline 0,93 & $19^{\circ}$ & $\begin{array}{l}\text { Mam- } \\
\text { borê }\end{array}$ & 0,91 & $101^{\circ}$ & $\begin{array}{l}\text { Novo } \\
\text { Itacolo- } \\
\text { mi }\end{array}$ & 0,89 & $183^{\circ}$ & Catanduvas \\
\hline 0,93 & $20^{\circ}$ & Ipiranga & 0,91 & $102^{\circ}$ & $\begin{array}{l}\text { Canta- } \\
\text { galo }\end{array}$ & 0,89 & $184^{\circ}$ & Terra Boa \\
\hline \multicolumn{3}{|c|}{20 mais eficientes - Cluster 4} & \multicolumn{3}{|c|}{20 intermediários - Cluster 4} & \multirow{2}{*}{\multicolumn{3}{|c|}{20 menos eficientes - Cluster 4}} \\
\hline$[\ldots]$ pos & ăo $21^{\circ} \mathrm{c}$ & & {$[\ldots] \mathrm{pc}$} & $103^{\circ}$ & & & & \\
\hline
\end{tabular}

Fonte: os autores.

Como se pode verificar a partir dos resultados evidenciados na Tabela 8 (cluster 4), 184 foram os municípios que apresentaram as melhores previsões de receitas no período analisado, visto que esse grupo apresentou certa similaridade em seu desempenho, razão pela qual está agrupado em um mesmo cluster. Os municípios que pertencem a esse agrupamento são os que estão colocados entre o $1^{\circ}$ e o $184^{\circ}$ lugares no ranking TOPSIS $(0,89$ a 0,95$)$ elaborado nesta pesquisa. 
Os resultados encontrados revelam que as previsões alcançadas pelos municípios do Estado do Paraná são mais harmônicas, quando comparadas aos achados encontrados por Zonatto e Hein (2013), que investigaram essa temática em municípios gaúchos. Naquele caso, dos 496 municípios analisados, os autores constataram que, entre os exercícios 2005 e 2009 a maioria dos municípios gaúchos não obteve previsões eficientes.

Por sua vez, os municípios do Estado do Paraná demonstraram majoritariamente possuir uma previsibilidade mais eficiente. Apesar das limitações que restringem a comparabilidade desses resultados, uma possível explicação para a melhoria de tal desempenho pode estar relacionada aos efeitos da Lei de Responsabilidade Fiscal, a qual, em um espaço temporal mais amplo, como o investigado neste estudo, permite avaliar com maior dimensão a qualidade das previsões realizadas ao longo de um determinado período.

A Tabela 9 evidencia as distâncias entre os agrupamentos formados.

Tabela 9 - Distâncias entre centros de clusters finais formados

\begin{tabular}{rrrrrrr}
\hline Cluster & $\mathbf{1}$ & $\mathbf{2}$ & $\mathbf{3}$ & $\mathbf{4}$ & $\mathbf{5}$ & $\mathbf{6}$ \\
\hline 1 & &, 268 &, 187 &, 371 &, 121 &, 329 \\
2 &, 268 & &, 082 &, 102 &, 390 &, 061 \\
3 &, 187 &, 082 & &, 184 &, 308 &, 142 \\
4 &, 371 &, 102 &, 184 & &, 492 &, 042 \\
5 &, 121 &, 390 &, 308 &, 492 & &, 450 \\
6 &, 329 &, 061 &, 142 &, 042 &, 450 & \\
\hline Fonte: 0 os autores
\end{tabular}

Como se observa a partir dos resultados apresentados na Tabela 9, a maior distância $(0,492)$ existente é entre os clusters 4 e 5 , justamente os que apresentam o agrupamento dos municípios com a melhor e a pior previsões de receita. Por sua vez, a menor distância $(0,042)$ encontrada está concentrada entre os clusters 4 e 6 , agrupamentos com melhor eficiência de previsibilidade da receita pública. a Tabela 10 evidencia os resultados do teste de significância estatística da análise realizada. 
Tabela 10 - Teste ANOVA (significância Estatística)

\begin{tabular}{|c|c|c|c|c|c|c|}
\hline & \multicolumn{2}{|l|}{ Cluster } & \multicolumn{2}{|l|}{ Erro } & \multirow{2}{*}{$\mathbf{F}$} & \multirow{2}{*}{ Sig. } \\
\hline & Quadrado médio & df & Quadrado médio & Df & & \\
\hline TOPSIS & ,224 & 5 & ,000 & 377 & 946,436 & ,000 \\
\hline
\end{tabular}

Fonte: os autores.

Em síntese, observa-se, a partir dos resultados apresentados na Tabela 10, identificados por meio do teste ANOVA, que há significância estatística nos dados analisados, ao nível de 1\%. Dessa forma, torna-se possível a validação dos resultados encontrados nessa etapa da pesquisa.

\section{CONSIDERAÇÕES FINAIS}

Neste estudo objetivou-se a verificar o nível de eficiência e elaborar um ranking da previsibilidade da receita orçamentária dos municípios do Estado do Paraná no período compreendido entre os exercícios financeiros de 2002 a 2013. Para tanto, realizou-se uma pesquisa descritiva, mediante análise documental, com abordagem quantitativa dos dados. Foram analisadas as receitas prevista e arrecadada de 383 municípios paranaenses nesse período, com uso de técnicas estatísticas de análise de clusters e TOPSIS.

Os achados da pesquisa evidenciaram que no período analisado a maioria dos munícipios do Estado do Paraná apresentou eficiência na previsibilidade de receitas orçamentárias. Dos 383 municípios pesquisados, 99 alcançaram previsões com índice de eficiência superior a 0,91. Os municípios com melhor previsão orçamentária foram Guaporema, Altônia, Rio Negro, Rancho Alegre e Faxinal. Já os municípios com menor eficiência de previsibilidade foram Nova Olímpia e Palmas.

Comparativamente aos achados de estudos anteriores, verificou-se que um número maior de municípios desse Estado alcançou melhores previsões orçamentárias. Da mesma forma, observou-se maior harmonia entre o desempenho dos municípios que foram agrupados no cluster 4 e no 6, considerados respectivamente os agrupamentos com os municípios que obtiveram as melhores previsões orçamentárias nesse período. Os intervalos dos índices TOPSIS desses agrupamentos foram de 0,89 a 0,95 no cluster 4, que abrangeu 184 municípios, e de 0,89 a 0,84 no cluster 6, que agrupou 134 municípios. 
O intervalo encontrado no ranking geral elaborado para esta pesquisa entre as 300 melhores previsões identificadas corrobora tal constatação, uma vez que este apresentou uma variação de 0,9536 para o município com a melhor previsão $\left(1^{\circ}\right)$ e 0,8558 para o que alcançou a posição de número 300. Essas evidências permitem concluir que a maioria dos municípios do Estado do Paraná apresentou níveis elevados de eficiência em previsibilidade das receitas orçamentárias, considerando o desempenho alcançado no período compreendido entre os anos 2002 e 2013.

A qualidade das previsões orçamentárias favorece as atividades de planejamento, avaliação, controle e accountability, no que se refere à arrecadação e aplicação dos recursos públicos, preceitos básicos estabelecidos na LRF, coadunados com o artigo 37 da Constituição Federal de 1988, especificamente o princípio da eficiência. Compreender a qualidade da previsão de receitas pode fornecer indícios de municípios que apresentam maior ou menor eficácia na previsão de suas receitas e, por consequência, no seu planejamento orçamentário, o qual estabelece o conjunto de planos e metas a serem seguidos em determinado período. A identificação de clusters permite a verificação de municípios que alcançam previsões similares, os quais podem ser objeto de estudos de casos múltiplos, a fim de se avaliarem fatores que favorecem ou dificultam a previsão de receitas e a gestão orçamentária dos municípios.

Em contrapartida, constatou-se também que alguns municípios precisam melhorar seus processos de previsibilidade orçamentária. A realização de previsões inadequadas pode evidenciar má qualidade nas atividades de planejamento da gestão pública, o que pode impactar negativamente a execução de obras e investimentos públicos, bem como a manutenção de serviços considerados essenciais à população. Também tende a comprometer os processos de controle e accountability. Portanto, deve ser avaliada por gestores públicos, controladores internos e externos e a sociedade em geral.

De maneira geral, também foi possível constatar que o tamanho dos municípios, avaliado pelo número de habitantes, não influenciou a qualidade da eficiência da previsão da receita pública. Esses resultados revelam que, nesse período, não necessariamente municípios com maior número de habitantes possuem melhor previsibilidade de receitas orçamentárias. Tais achados estimulam a realização de novos estudos, de modo que se possa compreender em que condições o tamanho pode influenciar a previsibilidade de receitas e a gestão orçamentária dos municípios.

Os achados da pesquisa evidenciam que no período analisado (2002 a 2013), consoante o efeito da LRF, a eficiência da previsibilidade da receita orçamentária pode ter sido influenciada pela necessidade de maior responsabilidade da gestão fiscal. Esses resultados também fornecem evidências que estimulam a realização de no- 
vos estudos, com intuito de aprofundar a compreensão das relações existentes entre as práticas de gestão orçamentária, a eficiência de previsão de receitas e os efeitos de eventos que ocorreram na administração pública, como a adoção da LRF pelos municípios brasileiros.

Nessa perspectiva, a implantação de um Sistema de Informação de Custos em âmbito municipal também pode estimular a realização de novas investigações, com o propósito de se identificarem seus efeitos sobre as práticas de gestão do recurso público e a qualidade do gasto e dos processos de previsão de receitas e gestão orçamentária. A investigação a partir dos clusters aqui formados pode contribuir para a condução de estudos comparativos.

Investigações com a finalidade de compreender fatores que favorecem o desenvolvimento de melhores previsões orçamentárias se constituem uma lacuna de pesquisa relacionada a essa temática. Da mesma forma, a realização de análises comparativas ajuda a contribuir para o entendimento de diferentes práticas de gestão que podem favorecer ou prejudicar a elaboração de melhores previsões orçamentárias. A realização de estudos com o uso de novas metodologias para a previsão de receitas também deve ser incentivada, bem como a investigação da eficiência de previsibilidade em municípios de outras Unidades da Federação que ainda não foram estudados. Adicionalmente, é oportuna a realização de novas investigações buscando compreender o uso de práticas de controle gerencial no setor público, bem como seus efeitos sobre a gestão dos municípios brasileiros.

\section{REFERÊNCIAS}

\section{BEUREN, M. I. (Org.). Como elaborar trabalhos Monográficos em Contabili-} dade: Teoria e Prática. 3. ed. São Paulo: Atlas, 2008.

BRASIL. Constituição: República Federativa do Brasil de 1988. Brasília, DF: Senado Federal, 1988.

BRASIL. Lei complementar n. 101, de 04 de maio de 2000. Estabelece normas de finanças públicas voltadas para a responsabilidade na gestão fiscal e dá outras providências. Diário Oficial da União, Brasília, DF, 05 maio 2000.

BRASIL. Lei n. 4.320, de 17 de março de 1964. Estatui normas gerais de direito financeiro para elaboração e controle dos orçamentos e balanços da União, dos Estados, dos Municípios e do Distrito Federal. Diário Oficial da União, Brasília, DF, 04 maio 1964. 
CAMPELLO, C. A. G. B. Eficiência municipal: um estudo no Estado de São Paulo. 2003. Tese (Doutorado em Administração)-Universidade de São Paulo, São Paulo, 2003.

CRESWELL, J. W. Projeto de Pesquisa: Métodos Qualitativo, Quantitativo e Misto. 2. ed. São Paulo: Artmed, 2003.

FIGUEIRÓ, R. et al. Municípios: os bons resultados orçamentários se repetem em 2001. Informe-se BNDES, AFE, n. 49, p. 1-8, dez. 2002.

GABRIEL, S. A. et al. A multiobjective optimization model for project selection with probabilistic considerations. Socio-Economic Planning Sciences, v. 40, i. 4, p. 297-313, dec. 2006.

GIL, A. C. Métodos e técnicas de pesquisa social. 5. ed. São Paulo: Atlas, 2007.

GUZMÁN, C. A. El logro del value for money en la gestión pública: consideraciones en torno a los indicadores de eficiencia, eficacia y economía. Revista Contabilidade \& Finanças, v. 14, n. 32, p. 99-110, mayo/agosto 2003.

JUND, S. Administração Financeira e Orçamentária. 3. ed. São Paulo: Elsevier, 2008.

LEE, R. D.; JOHNSON, R. W. Public budgeting systems. 2. ed. Baltimore: University Park Press, 1977.

MINISTÉRIO DO PLANEJAMENTO, ORÇAMENTO E GESTÃO; SECRETARIA DE ORÇAMENTO FEDERAL. Manual Técnico do Orçamento - MTO - versão 2015. Disponível em: <http://www.orcamentofederal.gov.br/informacoes-orcamentarias/manual-tecnico/mto_2015_1a_edicao-150514.pdf>. Acesso em: 06 mar. 2015.

MWITA, J. I. A systems-based approach to public service quality. The International Journal of Public Sector Management, v. 13, i. 1, p. 19-37, 2000.

REIS, P. R. C.; COSTA, T. M. T.; SILVEIRA, F. R. S. Receita Pública e Bem-Estar Social nos Municípios Mineiros Emancipados no Período de 1988 A 1997. Revista Eletrônica de Administração, v. 19, n. 1, p. 61-82, 2013. 
ROCHA, M. M. Q. Análise do nível de eficiência no processo de previsão e arrecadação da receita pública dos municípios do Estado do Rio Grande do Norte. 2008. 106 p. Dissertação (Mestrado em Ciências Contábeis)-Universidade de Brasília, Universidade Federal da Paraíba, Universidade Federal do Rio Grande do Norte, Natal, 2008.

RUCKERT, I. N.; BORSATTO, M. L.; RABELO, M. As finanças municipais e os gastos sociais no Rio Grande do Sul - 1995-99. Documentos FEE, Porto Alegre: Fundação de Economia e Estatística Siegfried Emanuel Heuser, n. 50, 2002.

SACRAMENTO, A. R. S. Contribuições da lei de responsabilidade fiscal para o avanço da accountability no Brasil. Cadernos Gestão Pública e Cidadania, v. 10, n. 47, p. 21-50, jul./dez. 2005.

SANTOS, A. R. T.; ALVES, T. W. O impacto da lei de responsabilidade fiscal no desempenho financeiro e na execução orçamentária dos municípios no Rio Grande do Sul de 1997 a 2004. Revista de Administração Pública, v. 45, n. 1, p. 181-208, jan./fev. 2011.

SCARPIN, J. E.; SLOMSKI, V. Acurácia da previsão de receitas no orçamento antes e após a Lei de Responsabilidade Fiscal: um estudo de caso. Revista Universo Contábil, v. 1, n. 2, p. 23-39, maio/ago. 2005.

SLOMSKI, V. Manual de Contabilidade Pública. 3. ed. São Paulo: Atlas, 2013.

TZENG, G.-H.; HUANG, J.-J. Multiple Attribute Decision Making: Methods and Applications. 2011. Disponível em: <https://www.crcpress.com/>. Acesso em: 06 mar. 2015.

ZONATTO, V. C. S.; HEIN, N. Eficácia da previsão de receitas no orçamento dos municípios gaúchos: uma investigação empírica dos exercícios de 2005 a 2009 utilizando a análise de clusters. Revista Estudo CEPE, Santa Cruz do Sul, n. 37, p. 102-131, jan./jun. 2013.

ZONATTO, V. C. S.; RODRIGUES JÚNIOR, M. M.; TOLEDO FILHO, J. R. Aplicação do Modelo de Koyck na previsão de receitas públicas: uma análise das previsões orçamentárias realizadas pelos dez maiores Municípios em população no Estado do Rio Grande do Sul. RACE, Revista de Administração, Contabilidade e Economia, v. 13, n. 1, p. 249-276, jan./abr. 2014. 


\section{Como citar este artigo:}

\section{ABNT}

FIIRST, Clóvis et al. Eficiência de previsibilidade orçamentária da receita pública: um estudo em municípios do Estado do Paraná entre os exercícios 2002 e 2013.

RACE, Revista de Administração, Contabilidade e Economia, Joaçaba: Ed. Unoesc, v. 16, n. 3, p. 983-1008, set./dez. 2017. Disponível em: <http://editora.unoesc. edu.br/index.php/race>. Acesso em: dia/mês/ano.

\section{APA}

Fiirst, C., Pamplona, E., Hein, N., \& Zonatto, V. C. da S. (2017). Eficiência de previsibilidade orçamentária da receita pública: um estudo em municípios do Estado do Paraná entre os exercícios 2002 e 2013. RACE, Revista de Administração, Contabilidade e Economia, 16(3), 983-1008. Recuperado em dia/mês/ano, de http://editora.unoesc.edu.br/index.php/race 
